\title{
REFLECTIONS OF AN ANAESTHETIST RETURNING HOME
}

Friday, June 24th

The meeting is over and the family bus is rolling us home. Have just passed Oshawa where we left Ted Gain to pick up a new car. I sure hope the new Oldsmobile will hold together until they arrive in A.lberts.. At Oshawa, I turned the driving over to the girls and crawled into the back seat to dose and meditate. There has not been much time for contemplation the last few days.

It has been a very stimulating meeting: Too bad about the boys who had to stay home to do the work, and, particularly, those Toronto boys who did their share for the meeting, and, also, did the work. That does keep you busy!

Toronto was certainly the place to have this meeting, and what a reunion it was for the Varsity men after years away. Our teachers were all there. Doctors Shields, Stanley Campbell, Rupert Balfour, John Chassels, Bill Brown, and Norman Clark-the ones that used to put us to work and get us out of trouble. We like to remember that years ago there was no one handier with a laryngoscope and tube than Norman Clark; and, of course, Bill Brown told the "Cyclopropane Story." These men must be proud of the departments they have built; the University Department they have seen expand, function, and produce men and results. And, they are certainly producing! That paper by Stuart Vandewater on "Hypothermia in Neuro-surgery" was excellent; - and Code Smith's paper on "Paediatric Anaesthesia" was a good one too.

The programme was fine. It was a bit crowded at times, but, knowing the problems entailed in organizing a meeting of such scope, that was inevitable. There certainly was not time to take notes, but the Journat will have all the papers for more leisurely perusal and assimilation.

There could hardly have been better representation from all parts of Canada. Despite the sticky weather, everyone peeled off their coats and listened. Golfing was not much of a distraction. George Bigelow did the golfing for the whole meeting this year.

The representation from "South of the Border" was encouraging too. We have enjoyed their hospitality many times and, we hope, they enjoyed this trip to Canada.

The excellent representation from the United Kingdom made the meeting historical. All Canadians who have not been "over" recently were glad to meet the men whose articles they have found interesting and stimulating. Their contributions, both historical and scientific, were of a lhigh calibre. I am more convinced than ever that our Canadian trainées should all have the benefit of the influence and teaching available in Great Britain.

It was a pleasure to have Sir Robert MacIntosh there. He rapidly acquired the devotion and respect of all present, and his contributions to the meeting were more than scientific. His forthright attitude and refreshing humour will long be remembered. We could not have had a better ambassador at the General Sessions. 
Joe O'Donnell conducted the Annual Dinner well. Doctor Wesley Bourne was really up to form, and Sir Robert is one of the few who has ever been able to make an entertaining after-dinner speech out of the specialty of Anaesthesia. Where did all the people go during the dance? They could not possibly have all gone down to the pub.

And so it is overl And, a good thing it is that all appreciated the contributions made by Rod Gordon in organizing, entertaining, keeping meetings on schedule, and tactfully steering the immature new President through his first sessions. And Rod would, of course, have been quite helpless without Ruth at home, and Miss Campbell s.t the office.

We hope for health and adequate prosperity for a repetition of this experience in Edinburgh in 1959.

Well, we are getting near home. I'd better get into the front seat and do some of the driving. 